\title{
Heterochromatin protein 1 (HP1) connects the FACT histone chaperone complex to the phosphorylated CTD of RNA polymerase II
}

\author{
So Hee Kwon, ${ }^{1}$ Laurence Florens, ${ }^{1}$ Selene K. Swanson, ${ }^{1}$ Michael P. Washburn, ${ }^{1,2}$ Susan M. Abmayr, ${ }^{1,3}$ \\ and Jerry L. Workman ${ }^{1,4}$ \\ ${ }^{1}$ Stowers Institute for Medical Research, Kansas City, Missouri 64110, USA; ${ }^{2}$ Department of Pathology and Laboratory Medicine, \\ University of Kansas Medical Center, Kansas City, Kansas 66160, USA; ${ }^{3}$ Department of Anatomy and Cell Biology, University of \\ Kansas Medical Center, Kansas City, Kansas 66160, USA
}

\begin{abstract}
Heterochromatin protein 1 (HP1) is well known as a silencing protein found at pericentric heterochromatin. Most eukaryotes have at least three isoforms of HP1 that play differential roles in heterochromatin and euchromatin. In addition to its role in heterochromatin, HP1 proteins have been shown to function in transcription elongation. To gain insights into the transcription functions of HP1, we sought to identify novel HP1-interacting proteins. Biochemical and proteomic approaches revealed that HP1 interacts with the histone chaperone complex FACT (facilitates chromatin transcription). HP1c interacts with the SSRP1 (structure-specific recognition protein 1) subunit and the intact FACT complex. Moreover, HP1c guides the recruitment of FACT to active genes and links FACT to active forms of RNA polymerase II. The absence of HP1c partially impairs the recruitment of FACT into heat-shock loci and causes a defect in heat-shock gene expression. Thus, HP1c functions to recruit the FACT complex to RNA polymerase II.
\end{abstract}

[Keywords: HP1c; FACT; transcription elongation; heat-shock genes; HSP70]

Supplemental material is available at http://www.genesdev.org.

Received June 11, 2010; revised version accepted August 20, 2010.

Heterochromatin plays important roles in the maintenance of chromosome integrity and regulation of gene expression in eukaryotes (Grewal and Moazed 2003; Grewal and Jia 2007). A key property of heterochromatin is the association of heterochromatin protein 1 (HP1). HP1 proteins are highly conserved nonhistone chromosomal proteins (James and Elgin 1986) encoded by the Su(var)2-5 locus and act as a dosage-dependent modifier of position effect variegation (PEV) (Eissenberg et al. 1990). HP1 has two conserved domains-an N-terminal chromodomain (CD) and a C-terminal chromoshadow domain (CSD) - separated by a variable-length hinge region (Hin). HP1 proteins bind specifically to dimethylated and trimethylated $\mathrm{H} 3 \mathrm{~K} 9$ (H3K9me2 and $\mathrm{H} 3 \mathrm{~K} 9 \mathrm{me} 3$ ) via the $\mathrm{CD}$, a domain found in many chromosomal proteins (Grewal and Moazed 2003). As this modification is found mostly in silenced chromatin, HP1 has been considered a hallmark of repression. The CSD is required for HP1 dimerization and interaction with many proteins that

${ }^{4}$ Corresponding author.

E-MAIL jlw@stowers.org; FAX (816) 926-4692.

Article is online at http://www.genesdev.org/cgi/doi/10.1101/gad.1959110. possess a conserved pentapeptide motif, PXVXL (Boy et al. 2000; Brasher et al. 2000). Most eukaryotes contain several HP1 proteins that may fulfill slightly different functions. Mice and humans possess three main isoforms of HP1 (referred to as HP1 $\alpha, \mathrm{HP} 1 \beta$, and HP1 $\gamma$ ) (Kwon and Workman 2008). Drosophila also encodes three main isoforms of HP1 (HP1a, HP1b, and HP1c), which are ubiquitously expressed in the adult fly. Flies also have two tissue-specific isoforms (namely, HP1d/rhino and HP1e), which are expressed in ovaries and testes, respectively (Vermaak et al. 2005). HP1 paralogs display dramatic differences with respect to both their localizations and their functions. The Drosophila HP1a and HP1b and mammalian $\mathrm{HP} 1 \alpha$ and $\mathrm{HP} 1 \beta$ predominantly localize to heterochromatin, whereas HP1c and HP1 $\gamma$ localize to euchromatin (Minc et al. 2000; Fanti et al. 2003) and function in gene-specific silencing (Ayyanathan et al. 2003). The significance of this localization is not well understood, but has been proposed to reflect the multiple functions of HP1 proteins. HP1 has been well characterized as a silencer protein; however, depletion of HP1a leads to down-regulation of a subset of active genes (De Lucia et al. 2005), and H3K9me and HP1 $\gamma$ are enriched at 
the coding regions of actively transcribed genes in mammalian cells, suggesting a role in active transcription (Vakoc et al. 2005). In agreement with a euchromatin function, HP1a targets to highly expressed genes, including developmentally regulated genes and Hsp70, where it controls gene expression after heat shock (Biasin et al. 2003). Moreover, recent studies have shown that HP1a is a positive regulator of transcription by facilitating H3K 36 demethylation at active and/or heterochromatic regions (Lin et al. 2008), and that it positively regulates euchromatic gene expression by interacting with RNA transcripts and hnRNPs (heterogeneous nuclear ribonucleoproteins) in Drosophila (Piacentini et al. 2009). These data suggest that, in addition to its function in gene silencing, HP1 might also play an activating role in gene regulation.

Eukaryotic gene expression can be regulated at various steps in the transcription cycle /Weake and Workman 2010). Nucleosomes impose a strong block to elongation of RNA polymerase II (Pol II) transcription in vitro (Kireeva et al. 2002). Histone chaperones such as FACT (facilitates chromatin transcription) facilitate Pol II transcription elongation through nucleosomes (Orphanides et al. 1998, 1999; Belotserkovskaya et al. 2003). FACT is an evolutionarily conserved protein complex in eukaryotes, consisting of a heterodimer of SSRP1 (structurespecific recognition protein 1) and Spt16 (Schlesinger and Formosa 2000; Cao et al. 2003). FACT has roles in transcription, DNA replication, and DNA repair. In the transcription processes, FACT has effects on the fidelity of transcription initiation (Biswas et al. 2005; Cheung et al. 2008). FACT is colocalized with known elongation factors by chromatin immunoprecipitation (ChIP) (Squazzo et al. 2002), and mutants of FACT subunits in yeast show significant elongation defects (Formosa et al. 2002; Squazzo et al. 2002). In human cells, depletion of SSRP1 or Spt16 by siRNA affects expression of a common set of target genes as well as some unique genes (Li et al. 2007). In yeast, FACT depletion has both positive and negative gene-specific transcription effects (Jimeno-Gonzalez et al. 2006). Intriguingly, it has been reported in Schizosaccharomyces pombe that FACT contributes to centromeric heterochromatin formation via association with Swi6 (fission yeast homolog of HP1) independent of the RNAi machinery (Lejeune et al. 2007).

In addition to binding methylated H3K9 and KMT1 [SU(VAR)3-9], the canonical HP1a isoform has been shown to interact with many different proteins (Grewal and Jia 2007), explaining many functions of the HP1 in vivo. The fact that different partners mediate HP1 binding to different regions of the genome can account for the differential targeting of the three HP1 isoforms. However, the molecular mechanism by which HP1 regulates active transcription remains largely unknown. To investigate these issues, we isolated proteins interacting with the three HP1 isoforms by immunoaffinity purification and identified the FACT complex as a new partner of Drosophila HP1. We show that dSSRP1 interacts directly with HP1, and that this interaction is mediated by the central region of dSSRP1 and by the CSD of HP1. Interestingly, biochemical and immunolocalization data show that HP1c can link FACT with RNA Pol II in Drosophila. Moreover, loss of HP1c causes defects in localization of FACT to heat-shock puffs and in activation of HSP70 transcription. Based on these results, we propose that HP1c is a central protein in transcription activation, regulating heat-shock genes and contributing to the control of transcription elongation in concert with FACT and Pol II.

\section{Results}

All three HP1 isoforms interact with dSSRP1 within the FACT complex

Despite their similar domain architecture, the three HP1 isoforms in Drosophila (HP1a, HP1b, and HP1c) bind to different regions of the genome (Fanti et al. 2003). We therefore wondered whether the three HP1 isoforms have different interacting protein partners. We performed affinity purifications using ectopic-tagged HP1 proteins, and identified novel interaction proteins associated with the each Drosophila HP1 isoform. Nuclear extracts from stable cell lines expressing Drosophila HP1s with C-terminal Flag and HA tags were subjected to double Flag-HA affinity purification and analyzed by silver staining and MudPIT (multidimentional protein identification technology) (Washburn et al. 2001). We copurified proteins uniquely associated with each HP1 isoform as well as shared interactors, including previously described HP1associated proteins (Supplemental Fig. S1A). Interestingly, we identified peptides from each subunit of FACT in the purifications of all three isoforms of HP1 (Fig. 1A). To verify the interaction between FACT and HP1s, coimmunoprecipitation and pull-down assays were performed. As shown in Figure 1B, all HP1 isoforms and FACT were found to coprecipitate efficiently. To confirm these interactions, we coinfected Sf21 cells with baculovirus encoding Flag-tagged HP1c and HA-tagged dSSRP1 or dSpt16. Coomassie blue staining and Western blotting showed that HP1c copurified with only dSSRP1, but not dSpt16 (Fig. 1C). This interaction was also observed in an in vitro binding assay using recombinant HP1s and dSSRP1, followed by anti-HA immunoprecipitation. The result shown in Figure 1D indicates that HP1 and dSSRP1 proteins bind directly to each other. Importantly, the interaction is specific for HP1, as KDM4B, which is another HP1a interactor, failed to coimmunoprecipitate with dSSRP1. HP1c and HP1b interacted more strongly with dSSRP1 in vitro compared with HP1a. Interaction between HP1 and dSSRP1 was also observed with endogenous proteins from S2 cells, as shown in Figure 1E. Taken together, these results indicate that SSRP1 within the FACT complex is a bona fide novel specific interaction partner of all HP1 isoforms.

\section{The CSD of HP1 and the central region of ASSRP1 bind directly to each other}

To map the domain of HP1c required for interaction with dSSRP1, we purified truncated forms of HP1 that contain either the CD, hinge, or CSD, alone or in combination, 
A

\begin{tabular}{|c|c|c|}
\hline \multirow{2}{*}{ Protein } & \multicolumn{2}{|c|}{ Total peptides, \% coverage } \\
\cline { 2 - 3 } & dSSRP1 & dSpt16 \\
\hline HP1a & $64,31.8 \%$ & $92,38.8 \%$ \\
\hline HP1b & $60,29.7 \%$ & $82,35.2 \%$ \\
\hline HP1c & $94,45.4 \%$ & $113,50.9 \%$ \\
\hline
\end{tabular}

B

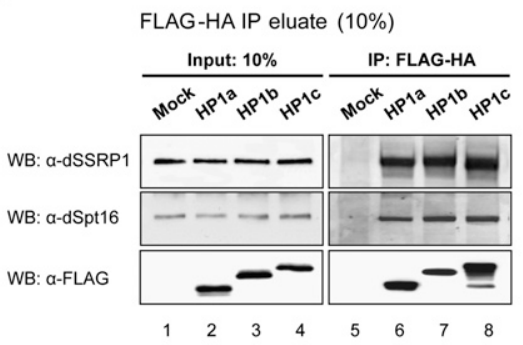

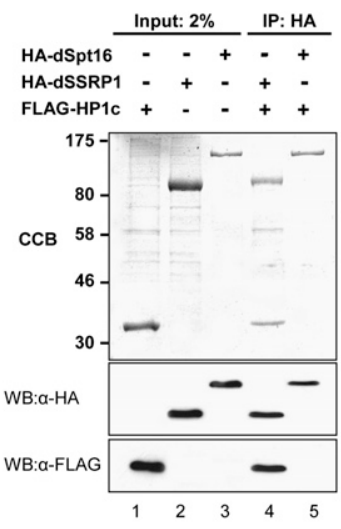

E
D

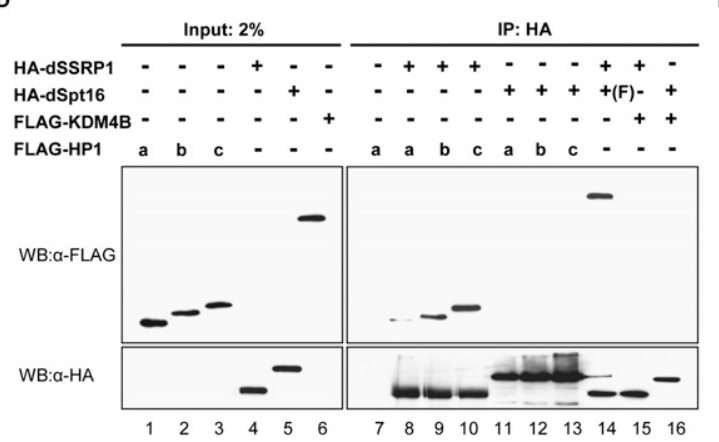

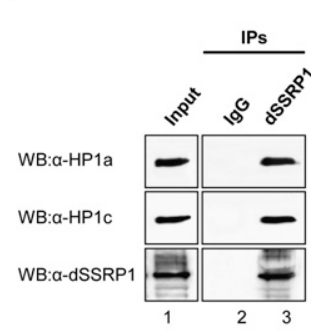

Figure 1. Identification of the dFACT complex as a novel Drosophila HP1-interacting protein. (A) MudPIT analysis of native Drosophila HP1associated proteins purified from HAFlag-tagged dHP1-expressing stable cells under $0.1 \mathrm{mM}$ $\mathrm{CuSO}_{4}$ induction. The table lists the number of nonredundant spectra (total peptides) and the amino acid sequence coverage. $(B)$ The eluate of tandem affinity purification from wild-type S2 cells (control) and dHP1-expressing cells was analyzed by Western blot using the indicated antibodies. $(C)$ Ectopic-tagged recombinant proteins were purified from Sf21cells infected with baculovirus encoding Flag-HP1c (lane 1), HAdSSRP1 (lane 2), or HA-dSpt16 (lane 3), or coinfected with baculovirus encoding Flag-HP1c and HA-dSSRP1 (lane 4) or HA-Spt16 (lane 5). The eluate from anti-Flag or anti-HA beads was visualized by Coomassie blue staining and analyzed by Western blot. (D) HP1c interacts specifically with dSSRP1, but not dSpt16. Recombinant dSSRP1 and HP1a, HP1b, or HP1c were mixed with $0.1 \mathrm{mg} / \mathrm{mL}$ BSA to reduce background binding. The resulting complexes were immunoprecipitated using anti-HA agarose. Beads and input $(2 \%)$ were analyzed by Western blot using anti-Flag and anti-HA antibodies. $(E)$ Coimmunoprecipitation assay with endogenous proteins. S2 cell extracts were immunoprecipitated with an anti-dSSRP1 antibody, followed by immunoblotting with the dSSRP1 antibody. Ten percent of total cell lysates used in immunoprecipitation are shown as input.

and examined them in the in vitro binding assays. As seen in Figure 2C, the CSD contained within the C-terminal region is sufficient and necessary for the binding of $\mathrm{HP} 1 \mathrm{c}$ to dSSRP1, while the CD or hinge do not interact with dSSRP1 under the same conditions. Further tests with the HP1a protein confirmed that the CSD was responsible for binding dSSRP1. The HP1a CSD domain alone, which does not contain the extended C-terminal region, was sufficient for the binding of dSSRP1 (Supplemental Fig. S2). The CSD appeared to bind to dSSRP1 with a higher affinity than did either the full-length protein or the CSD + Hinge protein (Fig. 2C).

Certain amino acid substitutions within the HP1 CSD disrupt its dimerization and interaction with PxVxLcontaining proteins (Lechner et al. 2000; Thiru et al. 2004). To dissect the interaction between dSSRP1 and the HP1c CSD further, we introduced two point mutations at conserved residues within the CSD, I129E, and Y138A. These residues were chosen by aligning the amino acid sequence of HP1c (Supplemental Fig. S3) with Drosophila HP1a and mouse HP1 $\beta$, where these residues were shown to be important (Brasher et al. 2000; Thiru et al. 2004). Therefore, the analogous I129E amino acid substitution was generated in HP1c. In contrast to wild-type HP1c, the HP1c I129E mutant failed to dimerize in vitro (data not shown). In HP1a, a W200A amino acid substitution disrupts interactions with PxVxL-containing proteins, yet retains its ability to dimerize (Brower-Toland et al.
2007). The analogous Y138A amino acid substitution in HP1c also disrupted interaction with $\mathrm{PxVxL}$ protein, but retained the ability to dimerize in vitro (data not shown). Recombinant HP1c-Y138A bound to dSSRP1 less strongly than the wild type (Fig. 2D), and HP1c-I129E failed to interact with dSSRP1, suggesting that an intact CSD dimerization interface is required for the HP1c-dSSRP1 interaction.

Next, a series of dSSRP1 deletion constructs were tested in a similar manner. The smaller subunit, dSSRP1, contains two structural domains: an SSRC motif and an HMG-box domain. Further sequence analysis reveals four evolutionarily conserved regions: an $\mathrm{N}$-terminal region, an acidic ID (intrinsically disordered) region, an HMG-flanking basic ID1 segment, and a mixed charge ID2 region at the extreme $C$ terminus (Tsunaka et al. 2009). The middle region of dSSRP1 (amino acids 209-433), containing the SSRC motif, was required for binding to HP1c, whereas the HMG motif, which is a DNA-binding domain, was dispensable (Fig. 2E). To further confirm this interaction region, we used purified recombinant yeast FACT proteins and Drosophila HP1s for in vitro binding assays. Unlike mammals and Drosophila, a bipartite yeast SSRP1 analog consists of Pob3 and Nhp6, which encodes an HMG motif (Brewster et al. 2001). Drosophila HP1 proteins were associated with the yPob3 but not the yNhp6 protein (Fig. 2F). Thus, HP1s interact with the SSRC motif region of dSSRP1 and yeast Pob3, the subunit of the yeast FACT 
A

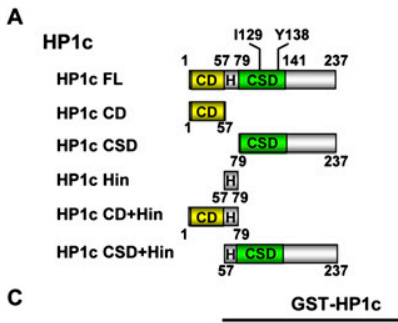

C

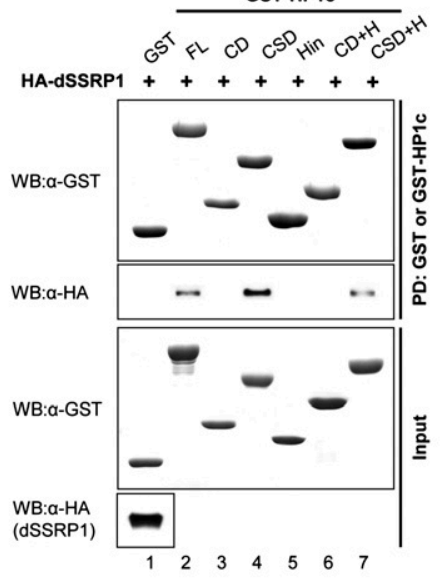

D

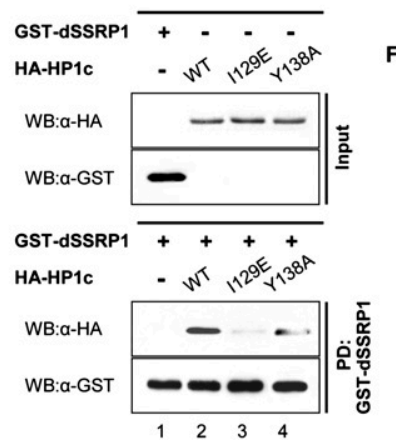

B

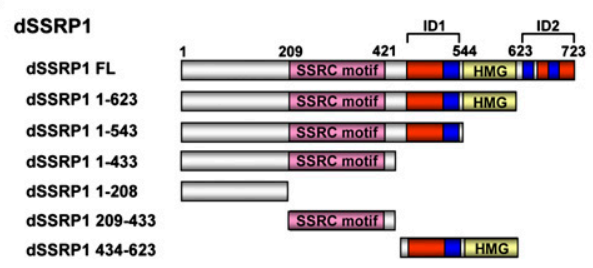

E

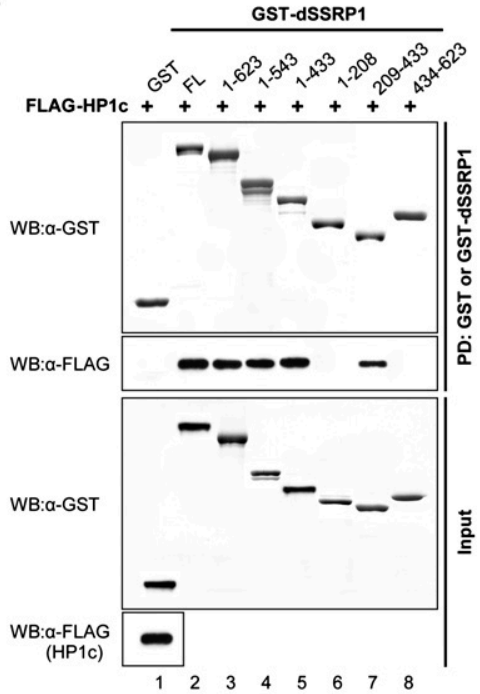

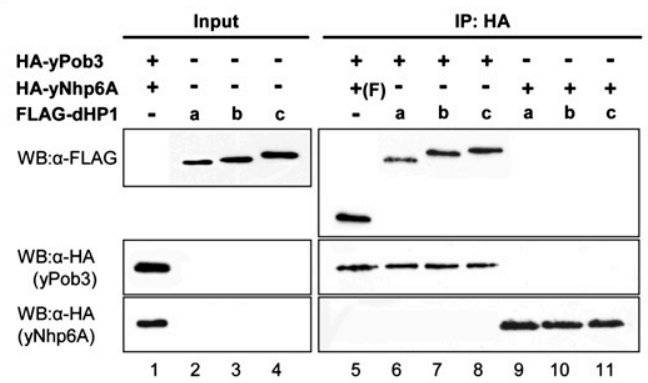

Figure 2. The CSD of HP1 and the central region of dSSRP1 are responsible for the HP1/ FACT interaction. (A) Schematic representation of HP1c truncation mutants and two critical residues of HP1c that are predicted to disrupt either its dimerization (I129E) or its target-binding interface (Y138A). Full-length HP1c (FL) contains a CD, a hinge domain (Hin), and a CSD. (B) dSSRP1 possesses the SSRC motif and HMGbox domain. The acidic and basic amino acidenriched regions of FACT are indicated in red and blue, respectively. (C) HP1c CSD, but not CD binds to dSSRP1. Indicated deletion derivatives of GST-HP1c were examined for binding to recombinant HA-dSSRP1. (D) HP1c mutant I129E fails to interact with dSSRP1, and another mutant, Y138A, partially disturbs the interaction with dSSRP1. Indicated HP1c mutants were analyzed for binding to GST-dSSRP1. $(E)$ The middle region of dSSRP1 is required for binding to HP1c. Indicated deletion derivatives of GSTdSSRP1 were assayed for binding to recombinant Flag-HP1c. $(F)$ The interaction between HP1c and dSSRP1 is not mediated by the HMG motif of dSSRP1. Recombinant dHP1c and yPob3 or yNhp6 were incubated with $0.1 \mathrm{mg} / \mathrm{mL}$ BSA and anti-HA agarose. $(F)$ The plus sign $(+)$ Indicates Flag-yNhp6A but not HA-Nhp6A. Beads and input $(2 \%)$ were analyzed by Western blot using the antibodies indicated in $C-F$. complex containing the SSRC motif. Collectively, the central region of dSSRP1 and the CSD of HP1 are necessary and sufficient for the interaction between these proteins.

\section{HP1c binds ASSRP1:dSpt16 dimers}

Although all three isoforms of HP1 bind to dSSRP1 in vivo and in vitro, the three HP1 proteins appeared to have different binding affinities for dSSRP1 (Fig. 1D). Because of this difference in affinity, we hypothesized that the three HP1 isoforms might compete for binding to dSSRP1. To test this hypothesis, we conducted in vitro binding assays mixing recombinant HP1 and dSSRP1 proteins, followed by anti-HA immunoprecipitation. We added different molar ratios of HP1c and HP1a protein. Increasing amounts of HP1c reduced the binding of HP1a to dSSRP1 (Fig. 3A,B). Conversely, titrating in HPla or HP1b displaced SSRP1-bound HP1c (Supplemental Fig. S5A,B). To further confirm this result, we added three HP1 isoforms in the same reaction and did an in vitro competitive binding assay. As seen in Figure 3C, HP1c showed the strongest binding to dSSRP1. However, it should be noted that each recombinant isoform can compete dSSRP1 from the others.

The FACT complex comprises a heterodimer: dSSRP1 and dSpt16 (Orphanides et al. 1999). However, the data above indicated that both HP1c and $\mathrm{dSpt} 16$ proteins can bind to dSSRP1. Thus, it was important to determine whether binding of HP1c and dSpt16 to dSSRP1 was mutually exclusive. We examined the effect of HP1c on the heterodimerization of FACT using an in vitro competitive binding assay with differentially tagged recombinant proteins. We added different molar ratios of dSSRP1 and HP1c protein and pulled down with HA-dSSRP1. The addition of increasing amounts of GST-HP1c progressively increased Flag-dSpt16 binding to the HA-dSSRP1 protein (Fig. 3D,E). Quantification showed a 65\% enhancement in FACT complex formation was reached when dSSRP1:dSpt16:HP1c were all present (Fig. 3E, lanes 2,5). In order to determine whether the association of HP1c is affected by Drosophila FACT complex versus dSSRP1 alone, we used purified, recombinant HA-dSSRP1/ 
A

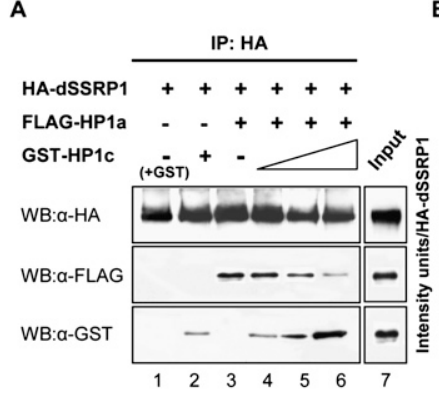

B

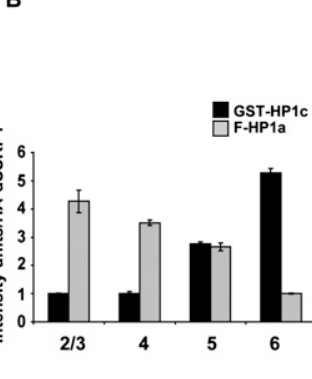

D
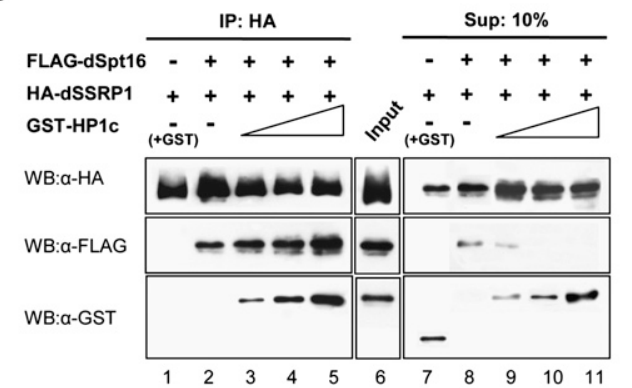

$\mathbf{F}$

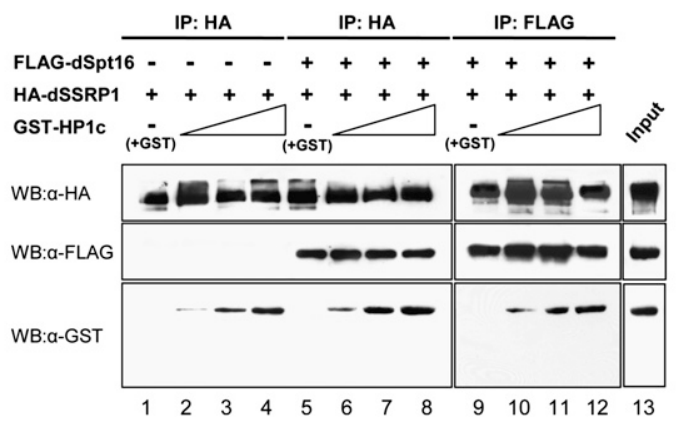

$c$

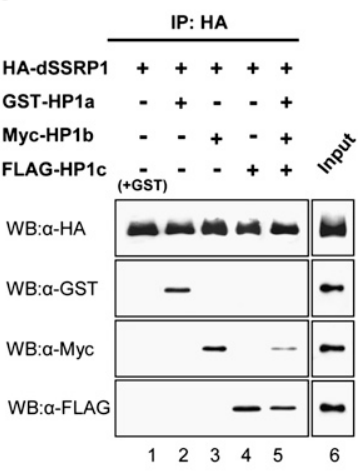

E

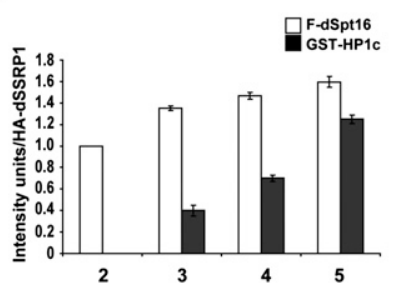

G

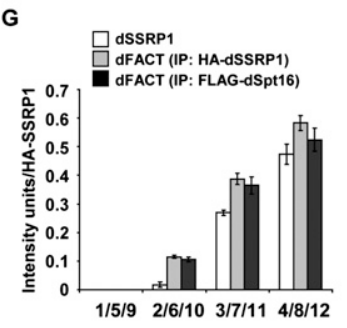

Figure 3. HP1 stimulates the formation of the FACT complex. $(A)$ In vitro competitive binding assay using recombinant dSSRP1 and HP1. The molar ratio of HP1a and HP1c is 1:0.5 (lane 4), 1:1 (lane 5), and 1:2 (lane 6). Recombinant dSSRP1 and either HP1a or HP1c, and/or both HP1s were incubated with $0.1 \mathrm{mg} / \mathrm{mL}$ BSA and anti-HA agarose. Beads and input $(2 \%)$ were analyzed by Western blot using the indicated antibodies. (B) Graph depicts the quantification of the normalized value of HP1c and HPla proteins over dSSRP1 described in $A .(C)$ In vitro competitive assay was performed as described in $A$. The molar ratio of HPla:HP1b: HP1c is 1:1:1. $(D)$ In vitro competitive assay using recombinant dSSRP1 and dSpt16 with addition of HP1c. The molar ratio of dSSRP1 and HP1c is 1:1 (lane 3), 1:2 (lane 4), and 1:4 (lane 5). (E) The graph depicts the ratio of HP1c or dSpt16 proteins over dSSRP1 described in $D$. $(F)$ Comparison of HP1c-binding affinity for a purified FACT complex and dSSRP1 alone. The molar ratio of dSSRP1 and HP1c is 1:0.5 (lanes 2,6,10), 1:1 (lanes 3,7,11), and 1:2 (lanes 4,8,12). (G) The graph depicts the ratio of HP1c protein over dSSRP1 described in $F$. $(B, E, G)$ The $X$-axis indicates lanes quantified from $A$, $D$, and $F$. Error bars indicates the standard deviation (SD) calculated from three independent experiments.
Flag-dSpt16 as well as HA-dSSRP1 alone in in vitro binding assays with HP1c. As shown in Figure 3, F and G, HP1c association is increased slightly when bound to the FACT complex compared with dSSRP1 alone. Thus, HP1c interaction with dSSRP1 is not mutually exclusive with dSSRP1:dSpt16 dimerization. Consistent with this result, $\mathrm{dSpt} 16$ was found to bind the N-terminal region of dSSRP1 that does not overlap with the SSRC motif region bound by HP1c (Supplemental Figs. S4, S5C). Furthermore, dSSRP1, which binds the HP1 CSD, inhibited the heterodimerization of HP1 proteins.

\section{HP1c links RNA Pol II and FACT}

We sought to determine whether the biochemical interactions between HP1s and FACT were important for their functions in vivo. To test this, we examined immunofluorescence staining of polytene chromosomes prepared from wild-type third instar larvae. Under nonheat-shock conditions, HP1c localizes preferentially to euchromatin, being mostly excluded from heterochromatin, in agreement with previous studies (Smothers and Henikoff 2001; Font-Burgada et al. 2008). Immunofluorescence experiments of polytene chromosomes have revealed that the global distribution of the FACT subunits dSSRP1 and dSpt16 overlaps with that of active Pol II. (Saunders et al. 2003). Consistent with the coimmunoprecipitation results above, HP1c showed strong colocalization with FACT along polytene chromosomes (Fig. 4A,C). Thus, HP1c and FACT interact biochemically and colocalize on polytene chromosomes, implying that their interaction is important in vivo.

Previous work demonstrated that FACT and HP1a are recruited onto the heat-shock loci upon heat shock (Biasin et al. 2003; Boehm et al. 2003). Our results raise the possibility that HP1c might play a role in the heatshock response in Drosophila, like HP1a. The Hsp70 loci in Drosophila have been used as a model system for studying transcription elongation: Normally, Pol II is paused on Hsp70, but, upon heat shock, p-TEFb phosphorylates the C-terminal domain repeats (CTD) of Rpb1 on Ser2, and thereby favors productive transcription (Lis et al. 2000). To determine whether HP1c accumulates at heat-shock-induced puffs, we performed immunofluorescence staining of polytene chromosomes following heat shock. We did not detect a significant presence of HP1c on these loci without heat-shock stress. However, in response to heat shock, we detected a strong association 
A
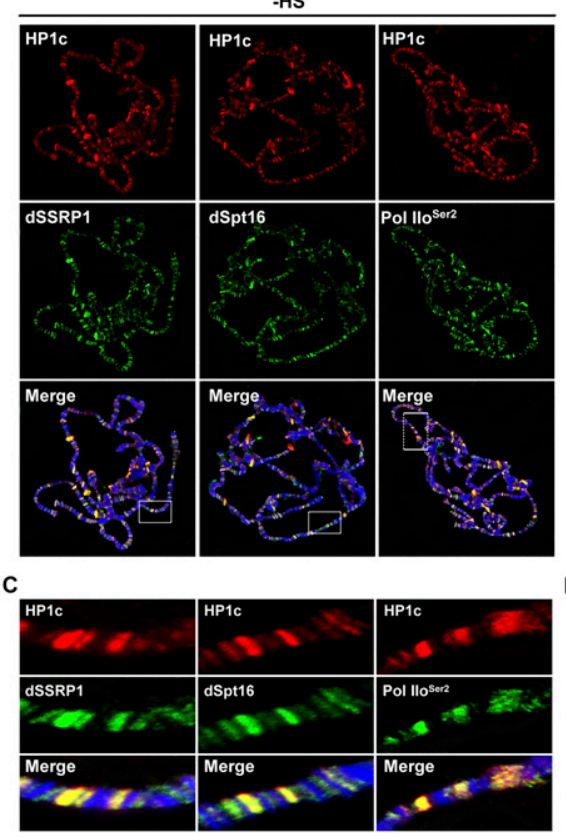

E
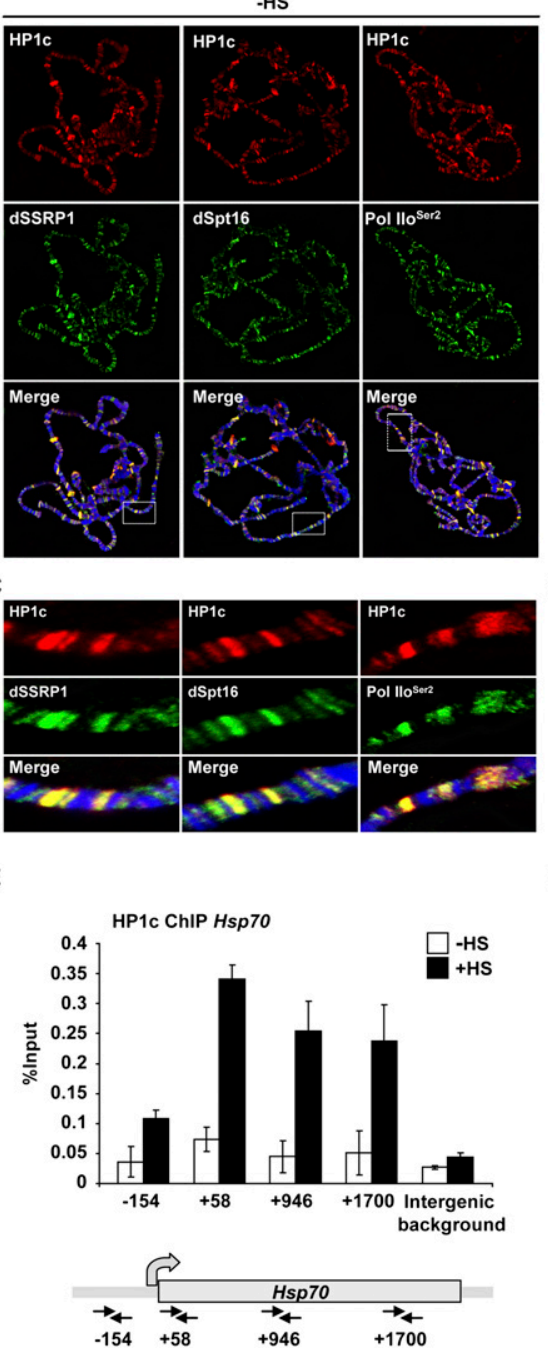

B
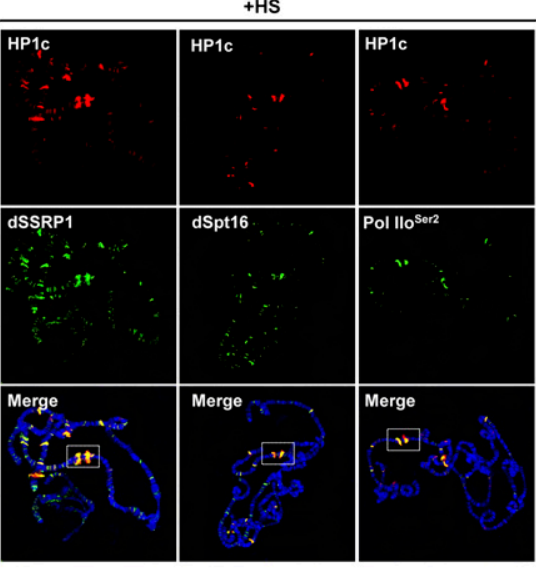

D

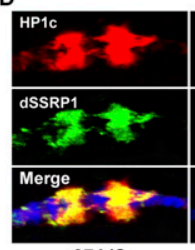

$87 \mathrm{~A} / \mathrm{C}$

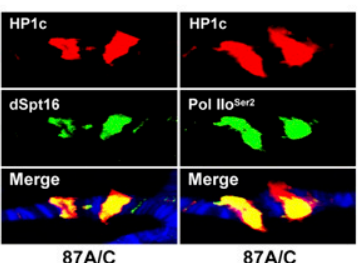

$\mathbf{F}$

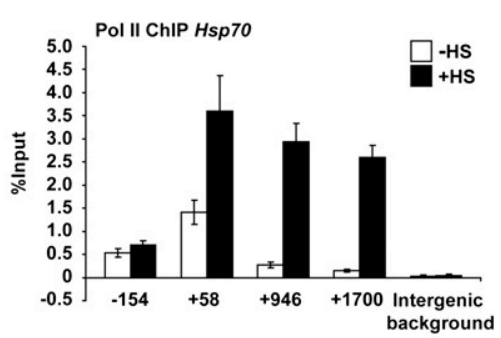

Figure 4. HP1c associates and colocalizes with FACT and Pol II on active chromatin regions. $(A, B)$ Polytene chromosome preparations from wild-type Oregon $\mathrm{R}$ (Ore-R) Drosophila larvae triple-labeled with dSSRP1, dSpt16, or Pol IIo ${ }^{\text {Ser2 }}$ antibodies (green); HP1c antibody (red); and DAPI (DNA; blue) without or with heat-shock treatment $\left(20 \mathrm{~min}\right.$ at $\left.36.5^{\circ} \mathrm{C}\right) .(C, D)$ The boxed areas from $A$ shown at a higher magnification. $87 \mathrm{~A}$ and $87 \mathrm{C}$ are the major heat-shock loci. $(E, F)$ Non-heat-shocked and heat-shocked S2 cells were used in ChIP-qPCR assays with HPlc and Pol II CTD antibody recognizing unphosphorylated and phosphorylated forms of Pol II. Numbers below each bar represent the position of real-time PCR primers relative to the Hsp70 transcription start site, as depicted at the bottom of $E$. The intergenic background primer pair targets a region $32 \mathrm{~kb}$ downstream from the last Hsp70 gene at the $87 \mathrm{C}$ genomic loci. Error bars represent the SD calculated from three independent experiments. of HP1c with the heat-shock loci. The accumulation of HP1c on heat-shock puffs was accompanied by a strong reduction of HP1c staining at nearly all euchromatic sites. As shown in Figure 4, B and D, HP1c colocalized extensively with FACT and the elongating form of Pol II on polytene chromosomes at major heat-shock loci, including the $H s p 70$ genes at $87 \mathrm{~A}$ and $87 \mathrm{C}$. Furthermore, we performed a ChIP analysis to determine whether HP1c is associated physically with Hsp70 upon heat shock. Our ChIP results showed that HP1c was enriched in $H s p 70$ and tracked along the gene with patterns similar to Pol II (Fig. 4E,F). In contrast, we did not observe substantial enrichment of HP1a at Hsp70 (Supplemental Fig. S6). Overall, these data indicate that HP1c and FACT are recruited rapidly to endogenous heat-shock loci, resulting in the remobilization of this protein from its euchromatic sites. This finding is supported by observations that heat-shock treatment itself does not affect the overall amounts of either HP1a or HP1c produced in larvae (see Fig. 7D, below).

HP1c localization is restricted to interbands, which correspond to gene-rich regions that stain poorly with
DAPI, suggesting an active role in transcriptional regulation. To address the potential contribution of HP1c in gene activity, we tested the distribution of Pol II and HP1c labeling on polytene chromosomes. Under nonheat-shock conditions, HP1c and active forms of Pol II costained significantly. Following heat shock, Pol II redistributed very prominently to heat-shock-induced puffs. Merging of the HP1c and Pol II (Pol $\left.\mathrm{IIo}^{\text {ser2 }}\right)$ images revealed a striking coincidence of these proteins (Fig. 4AD). Furthermore, as confirmed by immunoblot analysis (Fig. 5A,B), HP1c interacted more robustly with phosphorylated Pol II both in vivo and in vitro. In contrast, even though HP1c colocalized with active histone markers, HP1c did not interact with histone $\mathrm{H} 3$ peptides bearing either $\mathrm{K} 4 \mathrm{me} 2$ or $\mathrm{K} 36 \mathrm{me} 3$ modifications in vitro, although it did bind peptides with K9me2 and K9me3 marks (Supplemental Fig. S7). The cytological colocalization of HP1c with phosphorylated Pol II strongly suggests that HP1c is intimately involved in Pol II transcription.

Next, we examined the direct interaction between FACT and Pol II using a CTD peptide pull-down assay. To do this, the Drosophila FACT complex was reconstituted 
A

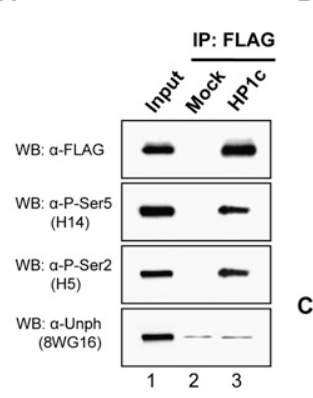

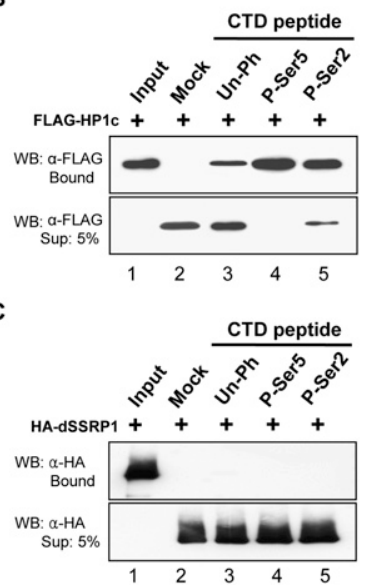

D

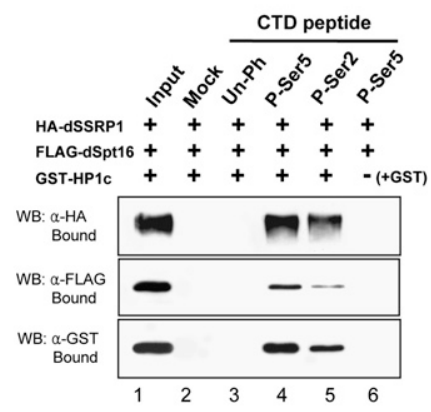

Figure 5. HP1c is a mediator between FACT and transcriptionally engaged Pol II. (A) Coimmunoprecipitation of HP1c with RNA Pol II. S2 nuclear extracts from a stably Flag-HP1c-expressed cell line were immunoprecipitated with an anti-Flag antibody, followed by immunoblotting with the indicated RNA Pol II antibodies. Ten percent of total cell lysates used in immunoprecipitation are shown as ifnput. $(B-D)$ CTD peptide pull-down assay of HP1c, dSSRP1, and HP1c + FACT. from purified recombinant HA-dSSRP1 and Flag-dSpt16. HP1c was able to bind to all CTD peptides, although association was increased for the phosphorylated CTD peptides. In contrast, neither dSSRP1 nor dSpt16 interacted directly with any form of CTD peptide in the same conditions where HP1c bound to Pol II CTD peptides (Fig. 5B,C; Supplemental Fig. S8). However, in the presence of HP1c, both the dSSRP1 and dSpt16 subunits of FACT were pulled down with CTD peptides phosphorylated on Ser2 or Ser5 (Fig. 5D). The addition of GST alone did not enhance the binding of FACT subunits to CTD peptides. These results indicate that HP1c bridges connect the FACT histone chaperone complex to the phosphorylated CTD of Pol II.

\section{HP1c specifies the recruitment of FACT into euchromatin}

To investigate the functional significance of HP1c in the localization of FACT and other HP1 isoforms, we immunolocated these proteins on the polytene chromosomes of wild-type as well as HP1c mutant larvae. As noted previously, in the wild type, HPla localizes predominantly to the chromocenter and the largely heterochromatic fourth chromosome (James et al. 1989; Fanti et al. 2003). In HP1c mutant larvae, HP1a and H3K9me2 were still present at the chromocenter. However, unexpectedly, we also detected diffuse spreading of HP1a to the euchromatic arms (Fig. 6A, top row, cf. the first and second panels and the third panel). In the wild-type larvae, FACT was distributed widely throughout the euchromatic chromosome arms (Saunders et al. 2003). However, in HP1c mutant larvae, we observed mislocalization of some fraction of FACT to the heterochromatic regions on polytene chromosomes (Fig. 6A, see boxed regions in the top right panels). In line with this finding, FACT showed significant colocalization with H3K9me2, a hallmark of heterochromatin, in mutant larvae lacking HP1c (Fig. 6B). Although the euchromatin association of FACT still occurred, its association was partially disturbed in the HP1c mutant background. From the results reported in Figure 6, it appears that FACT switches from HP1c to HP1a in the HP1c mutant, resulting in the appearance of some HPla in euchromatin (the normal FACT location) and some FACT in heterochromatin (the normal HPla location). This switch suggests that the strict localization of FACT to euchromatin depends on the presence of HP1c. To further verify the effect of the artificial targeting of FACT to a heterochromatin location by binding HPla, we measured the mRNA levels of the $F$ and 1360 elements. These are two transposable elements distributed in heterochromatin and known to be bound preferentially by HPla (De Lucia et al. 2005). The mRNA levels of both transposable elements were derepressed in the HP1 mutant backgrounds, although to different extents (Fig. 6C). These results further support our hypothesis that HP1c helps recruit FACT into euchromatin.

\section{Depletion of HP1c delays the recruitment of FACT to heat-shock-induced loci and reduces Hsp gene induction}

Our observation of the interaction between HP1c and FACT and their colocalization on heat-shock-induced loci suggests a possible role of HP1c in the heat-shock transcription response. To directly assess this possibility, we examined whether FACT is recruited to the heatshock puffs in the absence of HP1c. We first tested the fluorescence staining of FACT and active Pol II in a timecourse experiment following heat shock in the HP1cnull mutant larvae. The polytene chromosome immunostaining of HP1c mutant larvae upon heat shock revealed that the absence of $\mathrm{HP} 1 \mathrm{c}$ does not affect the formation of puffs and the accumulation of high levels of hyperphosphorylated Pol II (Fig. 7A, fourth column). Puffed regions could be identified clearly in HP1c-null mutants, as defined by the presence of strong Pol IIo ${ }^{\text {ser2 }}$ antibody labeling. This indicates that the formation of heat-shock puffs is likely to be functional in HP1c-null mutants. In contrast, in the HP1c mutants, FACT was not localized into the heat-shock loci within a 10 -min heat shock (Fig. 7A, second column), whereas, in wildtype larvae, FACT was already at the puffs after $10 \mathrm{~min}$ 
A

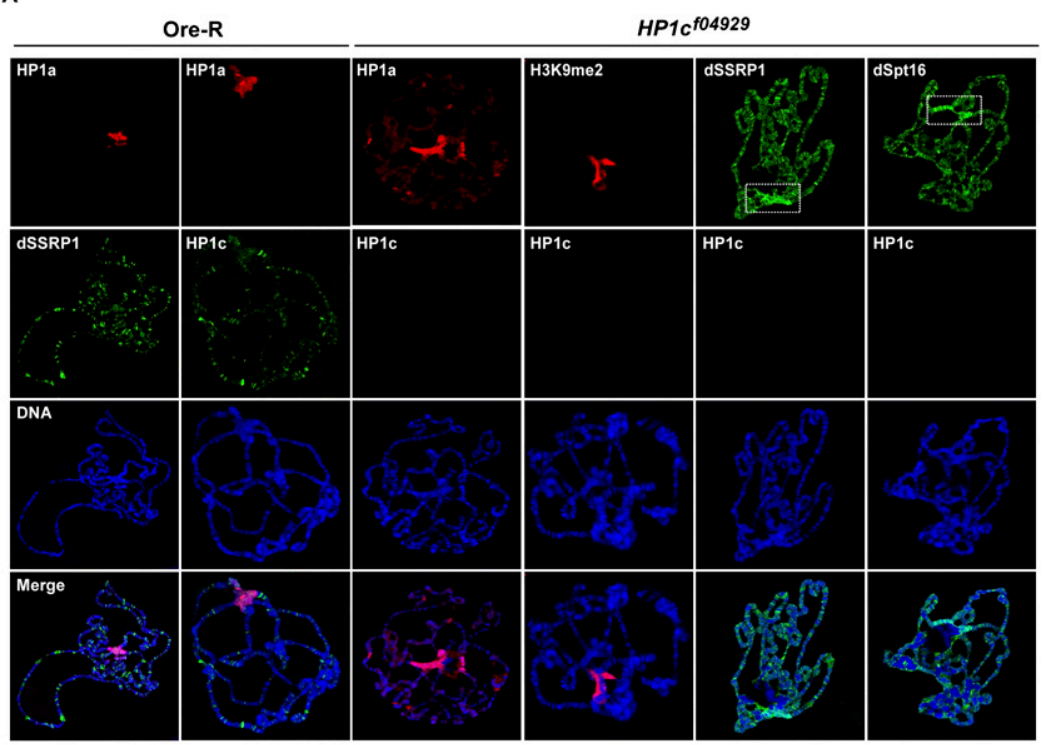

B

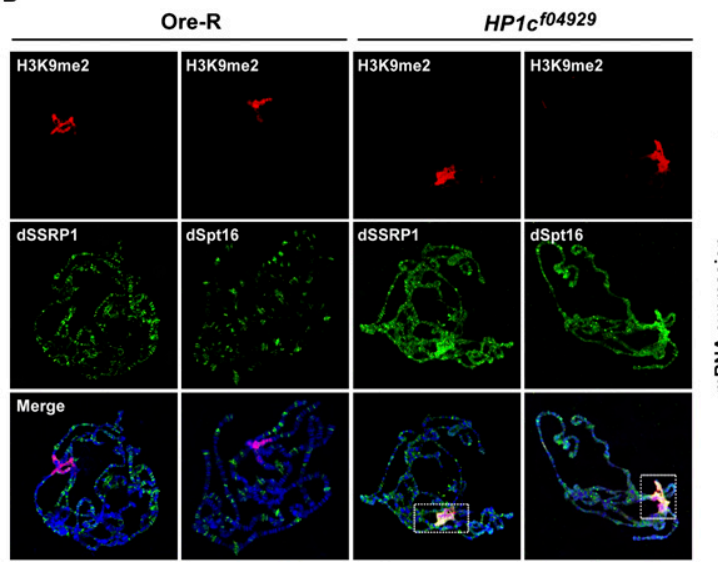

Figure 6. HP1c deficiency causes mislocalization of FACT and HP1a. $(A, B)$ Salivary gland polytene chromosomes from Ore-R and HP1cmutant $\left(H P 1 c^{f 04929}\right)$ larvae stained with dSSRP1, dSpt16, or HP1c antibodies (green); HP1a and H3K9me2 antibodies (red); and DAPI (DNA; blue). The boxed area shows heterochromatic regions where FACT was relocalized. $(C)$ Transcript levels of $F$ and 1360 element mRNA in Ore-R, HP1c $\left(H P 1 c^{f 04929}\right)$, and HP1a [Su(var)2$5^{04} / \mathrm{Su}(\mathrm{var}) 2-5^{05}$ ] mutant backgrounds. The transcript levels were determined by qRT-PCR and normalized to the mRNA levels of the RpL32. Numbers indicate derepressed fold relative to wild-type control larvae. of heat shock (Fig. 7A, fifth column). To further solidify these results, we quantitated the percentage of FACTpositive heat-shock puffs in both the wild type and HP1c mutants. From the data represented in Figure $7 \mathrm{~B}$, it is clear that the depletion of HP1c results in the delayed recruitment of FACT onto heat-shock puffs upon stress. Although FACT is recruited eventually onto the heatshock loci in larvae lacking HP1c, FACT redistribution to the puffs is delayed significantly. Thus, HP1c plays a critical role in hastening the recruitment of FACT onto heat-shock puffs.

To better define the role of HP1c and FACT in controlling the heat-shock response, we used quantitative RTPCR (qRT-PCR) to measure the transcription of the six, nearly identical genes that encode Hsp70 (the major heatshock protein in Drosophila) (Gong and Golic 2004) under heat-shock and non-heat-shock conditions. We also measured the mRNA levels of two constitutively expressed heat-shock genes: Hsp83 and Hsp26. We performed three independent experiments in duplicate for each sample in which total RNA was isolated from wild-type, $H P 1 c^{f 04929}$, and Su(var)2-5 $04 / \mathrm{Su}($ var)2-5 05 (HP1a mutant) larvae without or with heat shock. As illustrated in Figure 7C, very low levels of $H s p 70$ mRNA transcripts were detected in both wild-type and HP1 mutant backgrounds under nonheat-shock conditions. However, a robust increase in $H s p 70$ mRNA transcript levels, relative to rp49 transcript levels, was detected in response to heat-shock treatment in all three genotypes. Following heat-shock treatment, Hsp70 transcripts were induced $>270$-fold in wild-type larvae and $~ 90$-fold in HP1c-null mutant larvae (Fig. 7C). Also, heat shock increased transcript abundance by more than threefold, 1.8-fold, and 1.9-fold for hsp2 in wild-type, HP1a, and HP1c mutant larvae, respectively. This result reveals a modest decrease in hsp26 induction compared with $h s p 70$. Furthermore, we found an increase of $h s p 83$ mRNA levels by $>3.5$-fold and 2.5 -fold in wild-type and HP1a mutant larvae, respectively. This result shows a more subtle defect in hsp83 induction in only the HPla mutant. However, there were significant effects of HP1c depletion on the heat-shock-induced levels of hsp83 mRNA. Collectively, the effect of HP1c loss is more 
A
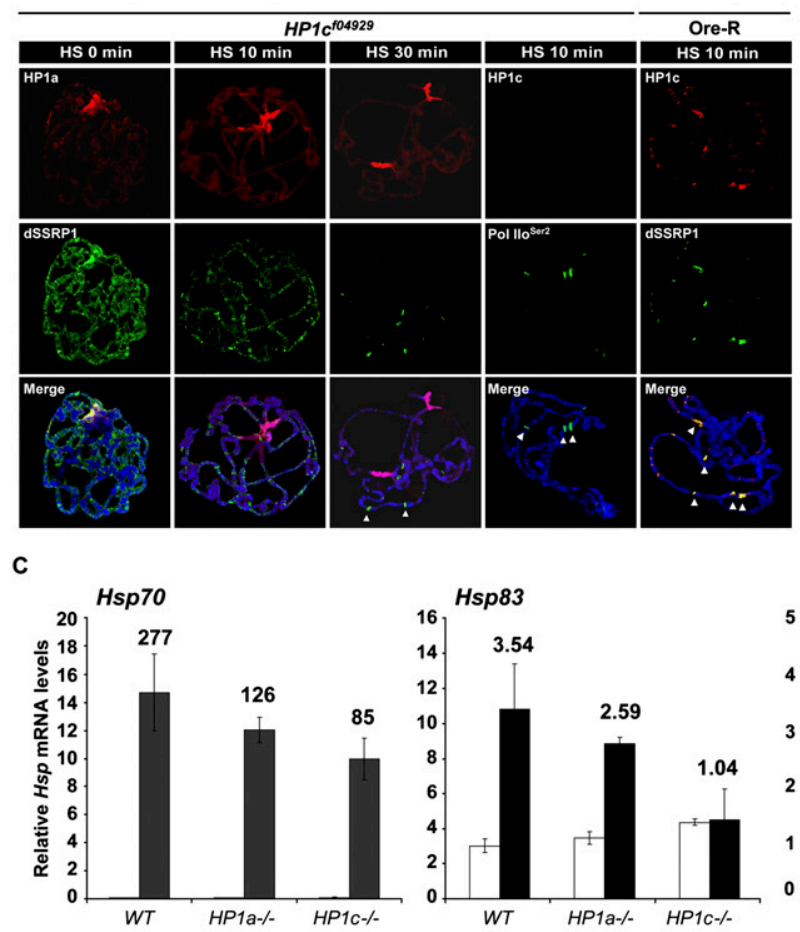

D

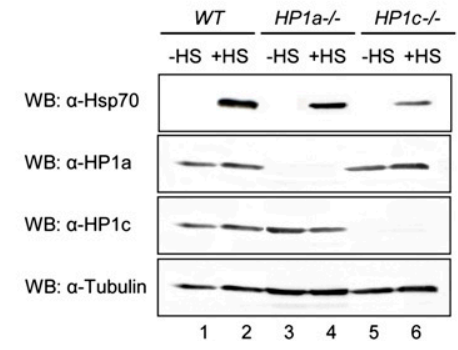

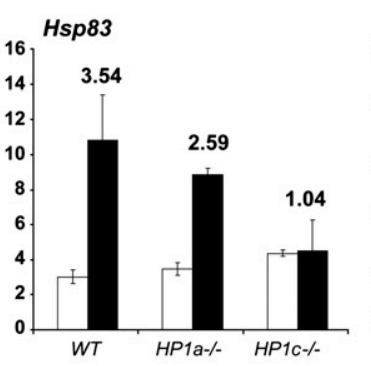

E

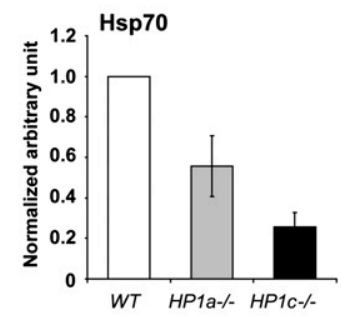

Figure 7. Analysis of FACT distribution and transcription at active loci during heatshock response in the HP1c mutant. $(A)$ Polytene chromosome preparations from Ore-R-null and HP1c $\left(H P 1 c^{f 04929}\right)$-null mutants. Drosophila larvae triple-labeled with dSSRP1 and Pol $\mathrm{IIo}^{\mathrm{Ser} 2}$ antibodies (green), HP1a and HP1c antibodies (red), and DAPI (DNA; blue) after the indicated heat-shock treatment. Arrowheads point to heat-shock puff regions. (B) Quantification of the percentage of polytene chromosome heatshock puffs positive for dSSRP1 described in $A$. More than 60 polytene chromosomes from nine slides were counted for each condition, and representative results are shown above. Student's $t$-test was used for statistical analysis; $\left(^{\star}\right) P<0.001$ versus wild-type control. $(C)$ Transcript levels of Hsp70, Hsp83, and Hsp26 mRNA in Ore-R, HP1c $\left(H P 1 c^{f 04929}\right)$, and HP1a [Su(var)2-5 ${ }^{04}$, $\mathrm{Su}($ var $) 2-5^{05}$ ] mutant backgrounds in response to heat-shock treatment. Expression levels were determined by qRT-PCR and normalized to RpL32 both without and after heat-shock treatment. Numbers indicate induction factors relative to control larvae without heat shock. $(D)$ Immunoblot of protein extracts from Ore-R, HP1c, and HP1a mutant third instar larvae without or with heat-shock treatment, labeled with the indicated antibodies. Labeling with $\alpha$-tubulin antibody was used as a loading control. (E) The graph depicts the quantification of the normalized value of Hsp70 proteins over $\alpha$-tubulin described in $D$. Error bars represent the SD calculated from three independent experiments. dramatic and pronounced on the expression of heat-shock genes than depletion of HP1a.

As expected, HSP70 protein was not detectable in wildtype and HP1 mutant untreated larvae. However, $20 \mathrm{~min}$ after heat-shock treatment, in mutant larvae, the protein was less abundant than in wild type (Fig. 7D,E). In wildtype larvae, the quantity of HP1s was not affected by the heat-shock treatment. This depletion of HP1a and HP1c caused a decreased expression of endogenous HSP70 protein and hsp70, hsp83, and hsp26 mRNA to different extents. The reduction in the HP1c mutant was greater than that observed in the HPla mutant. The loss of function of HP1s leads to defects in induction of heat-shock genes. We therefore conclude that HP1 acts to enhance heat-shock gene expression in response to thermal stress.

\section{Discussion}

\section{A novel HP1-interacting partner, FACT, has differential} interactions with three HP1 isoforms

Here, we identified the FACT complex as a novel interacting partner of HP1 through biochemical purification and coimmunoprecipitation. Consistent with our results, an association between HP1 and FACT has been shown by purification of TAP-tagged proteins in fission yeast, although no functional study was done (Fischer et al. 2009). In addition, we found through reciprocal purifications that HP1 peptides were detected in both dSSRP1 and dSpt16 purifications (Supplemental Fig. S1B). More importantly, we report differential association of the three HP1 proteins with FACT. HP1c and HP1b were found to interact preferentially with FACT both in vivo and in vitro, whereas HP1a interacted only weakly. Consistent with this result, previously known HP1-interacting proteins DDP1, hnRNP87F, and PEP (peptide on ecdysone puffs) have very different binding affinities for three HP1 isoforms (Supplemental Fig. S1A; Piacentini et al. 2009). However, upon overexpression of dSSRP1 or dSpt16, differences in HP1-binding affinities are abolished, suggesting that FACT localization is driven by changes in affinity based on the MudPIT data (Supplemental Fig. S1B). Despite the HP1s' structural and biochemical similarities, HP1a, HP1b, and HP1c are unlikely to be functionally redundant. HP1c, for example, shows a dramatically different localization pattern when compared 
with canonical HP1a. Despite binding of all three HP1 isoforms to H3K9me2 in vivo and in vitro, the cytological localizations of HP1c and HP1a are mutually exclusive. While HP1a localizes predominantly to pericentric heterochromatin, HP1c is excluded from heterochromatin in vivo unless it is overexpressed. Instead, HP1c colocalizes with active histone marks $\mathrm{H} 3 \mathrm{~K} 4 \mathrm{me} 3$ and $\mathrm{H} 3 \mathrm{~K} 36 \mathrm{me} 3$, as well as the hyperphosphorylated form of RNA Pol II (Font-Burgada et al. 2008), suggesting a role for HP1c in transcription activation rather than in repression. Indeed, while tethered HP1c up-regulates transcription of a reporter gene in flies, tethering of HP1a or HP1b causes transcriptional silencing. These data imply that different interacting proteins are responsible for the separate functions of each HP1 isoform. Recently, specific HP1cinteracting proteins have been identified by biochemical and proteomic approaches. For instance, two related transcription factors-WOC (without children) and ROW (relative of WOC)—both interact with HP1c via the PXVXL motif and coregulate a common set of genes with HP1c (Font-Burgada et al. 2008). However, although some isoform-specific partners have been studied, it remains unclear what recruits different combinations of HP1 homodimers or heterodimers to distinct regions of the genome. In terms of this, FACT would be a good example to explain an isoform-specific function of $\mathrm{HP} 1$, because HP1s have different affinities for FACT. Based on our findings and other reports, it is possible that each HP1 isoform and FACT might specifically regulate distinct target genes. Moreover, it will be interesting to further determine interactors of isoform-specific HP1s for elucidating their unique functions in different contexts.

\section{HP1s control the recruitment of FACT to euchromatin}

Nucleosomes impede transcription initiation and elongation by RNA Pol II. Effective transcription requires the reorganization of nucleosomes to allow for polymerase access to DNA. FACT is known to facilitate transcription through nucleosome perturbation that permits transcription initiation and elongation (Orphanides et al. 1998, 1999; Saunders et al. 2003). Furthermore, FACT has been identified in centromeric heterochromatin function in $S$. pombe via its association with Swi6 independent of the RNAi machinery (Lejeune et al. 2007). Although $s p$ FACT and Swi6 control transcription of the heterochromatic region, they are involved in transcription activation rather than repression. In fission yeast, CD proteins (Chp1/Chp2/ Swi6/Clr4) bind to methylated H3K9 and regulate pericentric heterochromatin. Among these four paralogs, Swi6 and Chp2, two HP1 orthologs, have been well-studied in heterochromatin formation. In contrast, $\mathrm{Chp} 1$ and $\mathrm{Clr} 4$ bind to transcriptionally active heterochromatin. Unlike other eukaryotes, fission yeast has not been reported to contain euchromatic HP1 homologs like Drosophila HP1c or mammalian HP1 $\gamma$. Hence, it implies that different combinations of HP1-like proteins may play a critical role in controlling transcription activation and repression in fission yeast.

In contrast to fission yeast, Drosophila and mammals have HP1 proteins that are able to function in euchro- matin. We show that HP1c is localized exclusively to euchromatin and associates with FACT and Pol II in active chromatin. Furthermore, depletion of HP1c leads to partial relocalization of FACT to heterochromatin. Indeed, HP1a binding to FACT results in increased expression of transposable elements located at heterochromatic loci, as HP1a is partially released from this heterochromatin site and may therefore become relocalized to euchromatin, thanks to its interaction with FACT. The transposable elements might also be up-regulated by the appearance of FACT in heterochromatin in the HP1c mutants. Thus, HP1 could be required for recruiting FACT to specific chromatin sites. If HP1c contributes to the stable recruitment of FACT, then loss of HP1c could lead to the accumulation of nonfunctional or improperly processed RNA species. This possibility is partially supported by the finding that HP1a is associated with RNA transcripts and hnRNPs, and is involved in RNA packaging and stability (Piacentini et al. 2009). However, whether HP1 directly links FACT and RNA processing during transcription elongation remains to be determined. Taken together, our finding suggests that Drosophila FACT might localize differentially in both euchromatic and heterochromatic regions and participate in both transcription activation and repression, depending on binding to the heterochromatic or euchromatic HP1.

\section{HP1s play a pivotal role in heat-shock response}

In contrast to the most commonly cited role of HP1 in heterochromatin formation and gene repression, recent studies have shown a clear association of HP1 with induced, actively transcribed genes, including transgenic, developmental, heat-shock-induced puffs in euchromatin (Piacentini et al. 2003; Vakoc et al. 2005). These data implicate that HP1 interacts with factors compatible with gene expression. Interestingly, a novel HP1-interacting protein, FACT, is also rapidly recruited to induced heatshock genes in response to heat shock (Saunders et al. 2003). The strong colocalization and the interactions of FACT and HP1c with active Pol II suggest that both HP1c and FACT are related to Pol II transcription at active chromatin. This point is further strengthened by the observation that, following thermal stress, these proteins redistribute and concentrate at the same heat-shock loci (Fig. 4A-D). Indeed, HP1c is associated with the Hsp 70 gene itself following heat shock, and its localization is almost identical to that observed for the Pol II (Fig. 4E,F), suggesting that HP1 could be involved in transcription elongation or stabilizing mRNAs. Also, FACT is enriched at the promoter and more at the $3^{\prime}$ coding regions of Hsp70, with kinetics of recruitment similar to Pol II and Spt6 upon heat shock (Saunders et al. 2003). In this regard, mislocalization of FACT to heterochromatin would be expected to impair heat-shock gene expression, resulting in a defective heat-shock response in the HP1 mutants. Indeed, loss of HP1c showed delayed recruitment of FACT to heat-shock loci and dramatically reduced transcript and protein levels of activated Drosophila Hsp70 in response to heat shock. We propose that the interaction 
with HP1c is critical for the localization of FACT in active chromatin, including heat-shock loci, and for heatshock gene regulation.

\section{HP1c functions as a molecular bridge between FACT and Pol II in transcription elongation}

We showed evidence for the physical and functional interaction of HP1c and FACT with active Pol II, as well as a physiological role for HP1c in heat-shock gene expression in Drosophila. Our studies have provided new insights into the importance of euchromatic HP1c in transcription activation in euchromatin. It is significant that HP1c is recruited in a manner spatially and temporally similar to that of chromatin-associated factors RNA Pol II and FACT. This result supports the idea that these proteins participate together in most, if not all, Pol II transcription elongation. In higher eukaryotes and yeast, in addition to Pol II, a role for FACT in transcription elongation is supported by biochemical studies showing that FACT associates with known elongation factors (Krogan et al. 2002; Simic et al. 2003), by ChIP, and by immunolocalization studies showing association of FACT with elongating Pol II and the PAF1 elongation complex (Krogan et al. 2002; Mason and Struhl 2003; Adelman et al. 2006; Pavri et al. 2006), as well as genetic interactions with mutations affecting elongation factors. (Formosa et al. 2002; Squazzo et al. 2002). However, it is not clear whether these elongation-associated proteins associate simultaneously with the FACT complex. Intriguingly, our findings indicated that FACT did not interact with Pol II directly, but associated with Pol II indirectly via HP1c in vitro (see Fig. 5). Thus, the FACT/ Pol II interaction needed a bridge protein: HP1c. In Saccharomyces cerevisiae, Set1 (KMT2) is recruited by the phosphorylated form of RNA Pol II at active genes (Krogan et al. 2003). S. pombe RNA Pol II recruits Swi6 into pericentric heterochromatin (Kato et al. 2005). Similarly, mammals show the parallel distribution of H3K4me3 and H3K9me3 at active genes, and HP1 $\gamma$ requires elongating Pol II for its recruitment (Vakoc et al. 2005). In this regard, it is noteworthy that a subset of active genes in Drosophila associates with and requires HPla for their expression (Piacentini et al. 2003; Cryderman et al. 2005). Based on our results, HP1 could be recruited by the active form of Pol II into euchromatin. The recruitment mechanism that deposits HP1 on active chromatin might result in targeting FACT to the appropriate location in chromatin. Therefore, we speculate that HP1-mediated FACT activity may serve as a regulatory mechanism to efficiently control transcription elongation by RNA Pol II in both heterochromatin and euchromatin.

\section{Materials and methods}

Fly stocks

Drosophila stocks were raised on standard food at $25^{\circ} \mathrm{C}$ unless noted otherwise. Oregon-R flies were used as a wild-type control. The HP1c P-element insertion mutant $H P 1 c^{f 04929}$ was obtained from the Bloomington Stock Center at Indiana University (stock no. 18819). Fly stocks Su(var)2-5 $5^{04} /$ Cyo-GFP and Su(var)2-5 5 / Cyo-GFP were provided by Sarah Elgin (Washington University, St. Louis, MO).

\section{DNA constructs}

The HP1a, HP1b, HP1c, dSSRP1, and dSpt16 cDNAs were cloned into the $\mathrm{S} 2$ cell expression vectors $\mathrm{pRmHa} 3-\mathrm{C}-\mathrm{HA}_{2} \mathrm{Flag}_{2}$ (Guelman et al. 2006), bacterial overexpression vector pGEX-4T-1, and pBacPAK8-N-HisFlag or pBacPAK8-N-2xHA vector (Invitrogen) for overexpression in insect cells. I129E and Y138A mutations of HP1c were generated using the QuikChange II XL Site-Directed Mutagenesis Kit (Stratagene).

\section{Cell lines, extract preparation, and protein purification}

Nuclear extracts from Drosophila melanogaster S2 cells stably expressing $\mathrm{HA}_{2} \mathrm{Flag}_{2}$-tagged $\mathrm{HP} 1$ (HP1-HF) or only $\mathrm{HA}_{2} \mathrm{Flag}_{2}$ tag as a negative control were tandem Flag and HA affinity-purified as described previously (Guelman et al. 2006). Eluates were analyzed by SDS-PAGE on $12 \%$ gels and silver staining, as well as MudPIT mass spectrometry, as described previously (Lee et al. 2005). Additional details are provided in the Supplemental Material.

\section{In vitro binding assay}

Recombinant Flag-HP1a, Flag-HP1b, Flag-HP1c, or Flag-HP1c mutants were incubated with either HA-dSSRP1 or HA-dSpt16 in buffer A $150 \mathrm{mM}$ HEPES at $\mathrm{pH} 7.9,300 \mathrm{mM} \mathrm{NaCl}, 2 \mathrm{mM}$ $\mathrm{MgCl}_{2}, 0.05 \%$ Triton X-100, 10\% [v/v] glycerol, 0.5 mM EDTA, $1 \mathrm{mM}$ PMSF, $0.1 \mathrm{mg} / \mathrm{mL} \mathrm{BSA}$ ) overnight at $4^{\circ} \mathrm{C}$. Proteins were pulled down with anti-HA agarose beads for $2 \mathrm{~h}$ at $4^{\circ} \mathrm{C}$. Beads were washed four times using buffer A and were eluted by boiling in SDS-PAGE sample buffer. Eluates and input $(2 \%)$ were analyzed by Western blot using anti-Flag and anti-HA antibodies (Sigma).

\section{Peptide pull-down assay}

Biotinylated CTD peptides or Histone tail peptides $(0.5 \mu \mathrm{g})$ were bound to $0.5 \mathrm{mg}$ of streptavidin-coated M280 Dynabeads (Invitrogen) in $50 \mu \mathrm{L}$ of high-salt-binding buffer B $(25 \mathrm{mM}$ Tris- $\mathrm{HCl}$ at $\mathrm{pH} 8.0,1 \mathrm{M} \mathrm{NaCl}, 1 \mathrm{mM}$ dithiothreitol, $5 \%$ glycerol, $0.03 \%$ Nonidet P-40) for $3 \mathrm{~h}$ at $4^{\circ} \mathrm{C}$. Beads were washed once with buffer $\mathrm{B}$ and twice with low-salt peptide-binding buffer C $(25 \mathrm{mM}$ Tris$\mathrm{HCl}$ at $\mathrm{pH} 8.0,50 \mathrm{mM} \mathrm{NaCl}, 1 \mathrm{mM}$ dithiothreitol, $5 \%$ glycerol, $0.03 \%$ Nonidet P- 40 ), and finally were resuspended in $50 \mu \mathrm{L}$ of buffer C. Recombinant protein $(0.5 \mu \mathrm{g})$ was mixed with the beads and incubated for $1 \mathrm{~h}$ at $4^{\circ} \mathrm{C}$ on a Dyna-Mixer (Dynal). Beads were washed three times with buffer $\mathrm{C}$ and then analyzed by SDSPAGE and Western blot.

\section{Preparation of Drosophila protein extracts}

Protein extracts were prepared from larvae that were not heatshocked, or were heat-shocked for $20 \mathrm{~min}$ at $36.5^{\circ} \mathrm{C}$. Fifty frozen third instar larvae were homogenized on ice in $300 \mu \mathrm{L}$ of extract buffer (20 mM HEPES at pH 7.9, 25\% glycerol, $400 \mathrm{mM} \mathrm{NaCl}, 1.5$ $\mathrm{mM} \mathrm{MgCl}_{2}, 0.2 \mathrm{mM}$ EDTA at $\mathrm{pH} 8.0,0.2 \%$ NP-40, $0.5 \mathrm{mM}$ PMSF, 0.5 mM DTT) using approximately five to 10 strokes of a Dounce homogenizer. Lysates were pelleted by centrifugation at $20,000 \mathrm{~g}$ for $20 \mathrm{~min}$ at $4^{\circ} \mathrm{C}$.

\section{Immunostaining of polytene chromosomes}

Heat-shocked $\left(20 \mathrm{~min}\right.$ at $\left.36.5^{\circ} \mathrm{C}\right)$ and non-heat-shocked third instar larvae were dissected in PBS supplemented with $0.1 \%$ 
Triton X-100. Salivary glands were fixed first in solution $1(3.7 \%$ paraformaldehyde, $1 \%$ Triton X-100 in PBS) for $30 \mathrm{sec}$ and then in solution 2 (3.7\% paraformaldehyde, $50 \%$ acetic acid) for 2 $\mathrm{min}$, and squashed. Chromosomes were spread on poly-L-lysinecoated microscope slides. Images were taken on a confocal laser scanning microscope (LSM-510 VIS, Carl Zeiss).

\section{Analysis of gene expression by $q R T-P C R$}

A two-step approach was taken in which the initial reverse transcription was followed by qPCR amplification. Total RNA was extracted from 10 pooled whole third instar larvae for each genotype (wild type, HP1 $c^{f 04929}$, and $\mathrm{Su}\left(\right.$ var) 2- $5^{04} / \mathrm{Su}$ (var)2-5 $5^{05}$ ) without or with heat shock $\left(20 \mathrm{~min}\right.$ at $\left.36.5^{\circ} \mathrm{C}\right)$ using the TRIzol Reagent (Invitrogen), RNAsecure (Ambion), and Turbo DNase (Ambion) following the manufacturers' instructions. cDNA derived from this RNA using SuperScript III Reverse Transcriptase (Invitrogen) was used as a template for qRT-PCR. mRNA levels were quantitated using a calibration curve based on known dilutions of concentrated cDNA. mRNA values from the larvae were normalized to that of rp49 (RpL32, FlyBase).

\section{Acknowledgments}

We thank Dr. Lori Wallrath for contributing anti-HP1a monoclonal antibody (C1A9) to Developmentaql Studies Hybridoma Bank, Dr. Axel Imhorf for the kind gift of anti-HP1c antibody, and Sarah Elgin for kindly sharing fly stocks. We are grateful to Chia-Hui Lin, Tamaki Suganuma, and Vikki Weake for technical suggestions, and to Michaela Smolle for critical reading of the manuscript. We thank the Workman laboratory members for stimulating discussions. This work was supported by the Stowers Institute for Medical Research.

\section{References}

Adelman K, Wei W, Ardehali MB, Werner J, Zhu B, Reinberg D, Lis JT. 2006. Drosophila Paf1 modulates chromatin structure at actively transcribed genes. Mol Cell Biol 26: 250-260.

Ayyanathan K, Lechner MS, Bell P, Maul GG, Schultz DC, Yamada Y, Tanaka K, Torigoe K, Rauscher FJ III. 2003. Regulated recruitment of HP1 to a euchromatic gene induces mitotically heritable, epigenetic gene silencing: A mammalian cell culture model of gene variegation. Genes Dev 17: 1855-1869.

Belotserkovskaya R, Oh S, Bondarenko VA, Orphanides G, Studitsky VM, Reinberg D. 2003. FACT facilitates transcription-dependent nucleosome alteration. Science 301: 10901093.

Biasin M, Boasso A, Piacentini L, Trabattoni D, Magri G, Deshmuks R, Deshpande A, Clerici M. 2003. IL-4 and CXCR4 upregulation in HIV-infected and uninfected individuals from Maharashtra-Mumbai. AIDS 17: 1563-1565.

Biswas D, Yu Y, Prall M, Formosa T, Stillman DJ. 2005. The yeast FACT complex has a role in transcriptional initiation. Mol Cell Biol 25: 5812-5822.

Boehm AK, Saunders A, Werner J, Lis JT. 2003. Transcription factor and polymerase recruitment, modification, and movement on dhsp70 in vivo in the minutes following heat shock. Mol Cell Biol 23: 7628-7637.

Boy MG, Six RH, Thomas CA, Novotny MJ, Smothers CD, Rowan TG, Jernigan AD. 2000. Efficacy and safety of selamectin against fleas and heartworms in dogs and cats presented as veterinary patients in North America. Vet Parasitol 91: 233-250.
Brasher SV, Smith BO, Fogh RH, Nietlispach D, Thiru A, Nielsen PR, Broadhurst RW, Ball LJ, Murzina NV, Laue ED. 2000. The structure of mouse HP1 suggests a unique mode of single peptide recognition by the shadow chromo domain dimer. $E M B O ~ J ~ 19:$ 1587-1597.

Brewster NK, Johnston GC, Singer RA. 2001. A bipartite yeast SSRP1 analog comprised of Pob3 and Nhp6 proteins modulates transcription. Mol Cell Biol 21: 3491-3502.

Brower-Toland B, Findley SD, Jiang L, Liu L, Yin H, Dus M, Zhou P, Elgin SC, Lin H. 2007. Drosophila PIWI associates with chromatin and interacts directly with HP1a. Genes Dev 21: 2300-2311.

Cao S, Bendall H, Hicks GG, Nashabi A, Sakano H, Shinkai Y, Gariglio M, Oltz EM, Ruley HE. 2003. The high-mobilitygroup box protein SSRP1/T160 is essential for cell viability in day 3.5 mouse embryos. Mol Cell Biol 23: 5301-5307.

Cheung V, Chua G, Batada NN, Landry CR, Michnick SW, Hughes TR, Winston F. 2008. Chromatin- and transcriptionrelated factors repress transcription from within coding regions throughout the Saccharomyces cerevisiae genome. PLoS Biol 6: e277. doi: 10.1371/journal.pbio.0060277.

Cryderman DE, Grade SK, Li Y, Fanti L, Pimpinelli S, Wallrath LL. 2005. Role of Drosophila HP1 in euchromatic gene expression. Dev Dyn 232: 767-774.

De Lucia F, Ni JQ, Vaillant C, Sun FL. 2005. HP1 modulates the transcription of cell-cycle regulators in Drosophila melanogaster. Nucleic Acids Res 33: 2852-2858.

Eissenberg JC, James TC, Foster-Hartnett DM, Hartnett T, Ngan V, Elgin SC. 1990. Mutation in a heterochromatin-specific chromosomal protein is associated with suppression of position-effect variegation in Drosophila melanogaster. Proc Natl Acad Sci 87: 9923-9927.

Fanti L, Berloco M, Piacentini L, Pimpinelli S. 2003. Chromosomal distribution of heterochromatin protein 1 (HP1) in Drosophila: A cytological map of euchromatic HP1 binding sites. Genetica 117: 135-147.

Fischer T, Cui B, Dhakshnamoorthy J, Zhou M, Rubin C, Zofall M, Veenstra TD, Grewal SI. 2009. Diverse roles of HP1 proteins in heterochromatin assembly and functions in fission yeast. Proc Natl Acad Sci 106: 8998-9003.

Font-Burgada J, Rossell D, Auer H, Azorin F. 2008. Drosophila $\mathrm{HP} 1 \mathrm{c}$ isoform interacts with the zinc-finger proteins WOC and Relative-of-WOC to regulate gene expression. Genes Dev 22: 3007-3023.

Formosa T, Ruone S, Adams MD, Olsen AE, Eriksson P, Yu Y, Rhoades AR, Kaufman PD, Stillman DJ. 2002. Defects in SPT16 or POB3 (yFACT) in Saccharomyces cerevisiae cause dependence on the $\mathrm{Hir} / \mathrm{Hpc}$ pathway: Polymerase passage may degrade chromatin structure. Genetics 162: $1557-1571$.

Gong WJ, Golic KG. 2004. Genomic deletions of the Drosophila melanogaster Hsp70 genes. Genetics 168: 1467-1476.

Grewal SI, Jia S. 2007. Heterochromatin revisited. Nat ReV Genet 8: 35-46.

Grewal SI, Moazed D. 2003. Heterochromatin and epigenetic control of gene expression. Science 301: 798-802.

Guelman S, Suganuma T, Florens L, Swanson SK, Kiesecker CL, Kusch T, Anderson S, Yates JR III, Washburn MP, Abmayr SM, et al. 2006. Host cell factor and an uncharacterized SANT domain protein are stable components of ATAC, a novel dAda2A/dGcn5-containing histone acetyltransferase complex in Drosophila. Mol Cell Biol 26: 871-882.

James TC, Elgin SC. 1986. Identification of a nonhistone chromosomal protein associated with heterochromatin in Drosophila melanogaster and its gene. Mol Cell Biol 6: 3862-3872. 
James TC, Eissenberg JC, Craig C, Dietrich V, Hobson A, Elgin SC. 1989. Distribution patterns of HP1, a heterochromatinassociated nonhistone chromosomal protein of Drosophila. Eur J Cell Biol 50: 170-180.

Jimeno-Gonzalez S, Gomez-Herreros F, Alepuz PM, Chavez S. 2006. A gene-specific requirement for FACT during transcription is related to the chromatin organization of the transcribed region. Mol Cell Biol 26: 8710-8721.

Kato H, Goto DB, Martienssen RA, Urano T, Furukawa K, Murakami Y. 2005. RNA polymerase II is required for RNAi-dependent heterochromatin assembly. Science 309: 467-469.

Kireeva ML, Walter W, Tchernajenko V, Bondarenko V, Kashlev M, Studitsky VM. 2002. Nucleosome remodeling induced by RNA polymerase II: Loss of the $\mathrm{H} 2 \mathrm{~A} / \mathrm{H} 2 \mathrm{~B}$ dimer during transcription. Mol Cell 9: 541-552.

Krogan NJ, Kim M, Ahn SH, Zhong G, Kobor MS, Cagney G, Emili A, Shilatifard A, Buratowski S, Greenblatt JF. 2002. RNA polymerase II elongation factors of Saccharomyces cerevisiae: A targeted proteomics approach. Mol Cell Biol 22: 6979-6992.

Krogan NJ, Dover J, Wood A, Schneider J, Heidt J, Boateng MA, Dean K, Ryan OW, Golshani A, Johnston M, et al. 2003. The Paf1 complex is required for histone $\mathrm{H} 3$ methylation by COMPASS and Dotlp: Linking transcriptional elongation to histone methylation. Mol Cell 11: 721-729.

Kwon SH, Workman JL. 2008. The heterochromatin protein 1 (HP1) family: Put away a bias toward HP1. Mol Cells 26: $217-$ 227.

Lechner MS, Begg GE, Speicher DW, Rauscher FJ III. 2000. Molecular determinants for targeting heterochromatin protein 1-mediated gene silencing: Direct chromoshadow domain-KAP-1 corepressor interaction is essential. Mol Cell Biol 20: 6449-6465.

Lee KK, Florens L, Swanson SK, Washburn MP, Workman JL. 2005. The deubiquitylation activity of Ubp8 is dependent upon Sgf11 and its association with the SAGA complex. Mol Cell Biol 25: 1173-1182.

Lejeune E, Bortfeld M, White SA, Pidoux AL, Ekwall K, Allshire RC, Ladurner AG. 2007. The chromatin-remodeling factor FACT contributes to centromeric heterochromatin independently of RNAi. Curr Biol 17: 1219-1224.

Li Y, Zeng SX, Landais I, Lu H. 2007. Human SSRP1 has Spt16dependent and -independent roles in gene transcription. I Biol Chem 282: 6936-6945.

Lin CH, Li B, Swanson S, Zhang Y, Florens L, Washburn MP, Abmayr SM, Workman JL. 2008. Heterochromatin protein 1a stimulates histone $\mathrm{H} 3$ lysine 36 demethylation by the Drosophila KDM4A demethylase. Mol Cell 32: 696-706.

Lis JT, Mason P, Peng J, Price DH, Werner J. 2000. P-TEFb kinase recruitment and function at heat shock loci. Genes Dev 14: 792-803.

Mason PB, Struhl K. 2003. The FACT complex travels with elongating RNA polymerase II and is important for the fidelity of transcriptional initiation in vivo. Mol Cell Biol 23: 8323-8333.

Minc E, Courvalin JC, Buendia B. 2000. HP1 $\gamma$ associates with euchromatin and heterochromatin in mammalian nuclei and chromosomes. Cytogenet Cell Genet 90: 279-284.

Orphanides G, LeRoy G, Chang CH, Luse DS, Reinberg D. 1998. FACT, a factor that facilitates transcript elongation through nucleosomes. Cell 92: 105-116.

Orphanides G, Wu WH, Lane WS, Hampsey M, Reinberg D. 1999. The chromatin-specific transcription elongation factor FACT comprises human SPT16 and SSRP1 proteins. Nature 400: $284-288$.
Pavri R, Zhu B, Li G, Trojer P, Mandal S, Shilatifard A, Reinberg D. 2006. Histone H2B monoubiquitination functions cooperatively with FACT to regulate elongation by RNA polymerase II. Cell 125: 703-717.

Piacentini L, Fanti L, Berloco M, Perrini B, Pimpinelli S. 2003. Heterochromatin protein 1 (HP1) is associated with induced gene expression in Drosophila euchromatin. J Cell Biol 161: 707-714.

Piacentini L, Fanti L, Negri R, Del Vescovo V, Fatica A, Altieri F, Pimpinelli S. 2009. Heterochromatin protein 1 (HP1a) positively regulates euchromatic gene expression through RNA transcript association and interaction with hnRNPs in Drosophila. PLoS Genet 5: e1000670. doi: 10.1371/journal.pgen. 1000670.

Saunders A, Werner J, Andrulis ED, Nakayama T, Hirose S, Reinberg D, Lis JT. 2003. Tracking FACT and the RNA polymerase II elongation complex through chromatin in vivo. Science 301: 1094-1096.

Schlesinger MB, Formosa T. 2000. POB3 is required for both transcription and replication in the yeast Saccharomyces cerevisiae. Genetics 155: 1593-1606.

Simic R, Lindstrom DL, Tran HG, Roinick KL, Costa PJ, Johnson AD, Hartzog GA, Arndt KM. 2003. Chromatin remodeling protein Chd 1 interacts with transcription elongation factors and localizes to transcribed genes. EMBO I 22: 1846-1856.

Smothers JF, Henikoff S. 2001. The hinge and chromo shadow domain impart distinct targeting of HP1-like proteins. Mol Cell Biol 21: 2555-2569.

Squazzo SL, Costa PJ, Lindstrom DL, Kumer KE, Simic R, Jennings JL, Link AJ, Arndt KM, Hartzog GA. 2002. The Paf1 complex physically and functionally associates with transcription elongation factors in vivo. EMBO I 21: 1764-1774.

Thiru A, Nietlispach D, Mott HR, Okuwaki M, Lyon D, Nielsen PR, Hirshberg M, Verreault A, Murzina NV, Laue ED. 2004. Structural basis of HP1/PXVXL motif peptide interactions and HP1 localisation to heterochromatin. EMBO J 23: 489499.

Tsunaka Y, Toga J, Yamaguchi H, Tate S, Hirose S, Morikawa K. 2009. Phosphorylated intrinsically disordered region of FACT masks its nucleosomal DNA binding elements. I Biol Chem 284: 24610-24621.

Vakoc CR, Mandat SA, Olenchock BA, Blobel GA. 2005. Histone $\mathrm{H} 3$ lysine 9 methylation and $\mathrm{HP} 1 \gamma$ are associated with transcription elongation through mammalian chromatin. Mol Cell 19: 381-391.

Vermaak D, Henikoff S, Malik HS. 2005. Positive selection drives the evolution of rhino, a member of the heterochromatin protein 1 family in Drosophila. PLoS Genet 1: 96-108.

Washburn MP, Wolters D, Yates JR III. 2001. Large-scale analysis of the yeast proteome by multidimensional protein identification technology. Nat Biotechnol 19: 242-247.

Weake VM, Workman JL. 2010. Inducible gene expression: Diverse regulatory mechanisms. Nat Rev Genet 11: 426-437. 


\section{Erratum}

Genes \& Development 24: 2133-2145 (2010)

Heterochromatin protein 1 (HP1) connects the FACT histone chaperone complex to the phosphorylated CTD of RNA polymerase II

So Hee Kwon, Laurence Florens, Selene K. Swanson, Michael P. Washburn, Susan M. Abmayr, and Jerry L. Workman

Due to an error in the figure preparation for the above-mentioned paper, there were faint "boxes" in view around some bands in Figures 1 and 5. This error has no effect on the conclusions of the paper; however, the figures have now been replaced online without the "boxes" in view. The authors apologize for any concern this may have caused. 


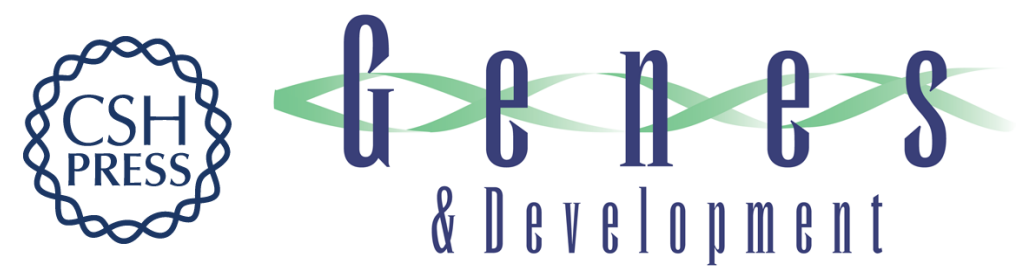

\section{Heterochromatin protein 1 (HP1) connects the FACT histone chaperone complex to the phosphorylated CTD of RNA polymerase II}

So Hee Kwon, Laurence Florens, Selene K. Swanson, et al.

Genes Dev. 2010, 24:

Access the most recent version at doi:10.1101/gad.1959110

Supplemental http://genesdev.cshlp.org/content/suppl/2010/09/27/24.19.2133.DC1
Material

Related Content Erratum: Heterochromatin protein 1 (HP1) connects the FACT histone chaperone complex to the phosphorylated CTD of RNA polymerase II

So Hee Kwon, Laurence Florens, Selene K. Swanson, et al.

Genes Dev. February , 2011 25: 287

References This article cites 55 articles, 30 of which can be accessed free at:

http://genesdev.cshlp.org/content/24/19/2133.full.html\#ref-list-1

Articles cited in:

http://genesdev.cshlp.org/content/24/19/2133.full.html\#related-urls

License

Email Alerting Receive free email alerts when new articles cite this article - sign up in the box at the top

Service right corner of the article or click here.

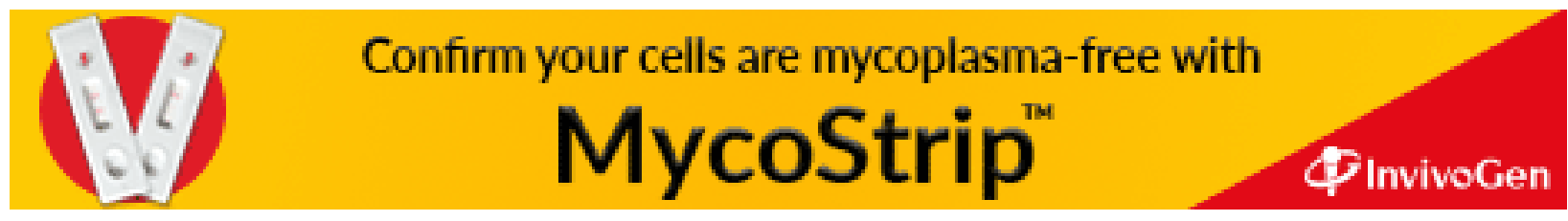

